\title{
ÁLBUM DE IMAGENS
}

\begin{abstract}
FOTOPINTURA CONTEMPORÂNEA: a pós-produção no trabaIho de Mestre Júlio
\end{abstract}

por Eduardo Queiroga

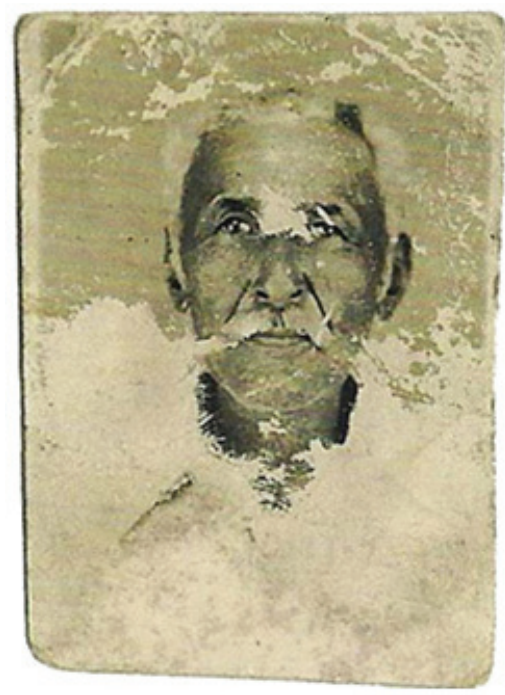

Fig. 1 - Exemplo de fotografia original deteriorada e fotopintura resultante Fonte: Júlio Santos, mestre da fotopintura (NAKAGAWA, 2010)

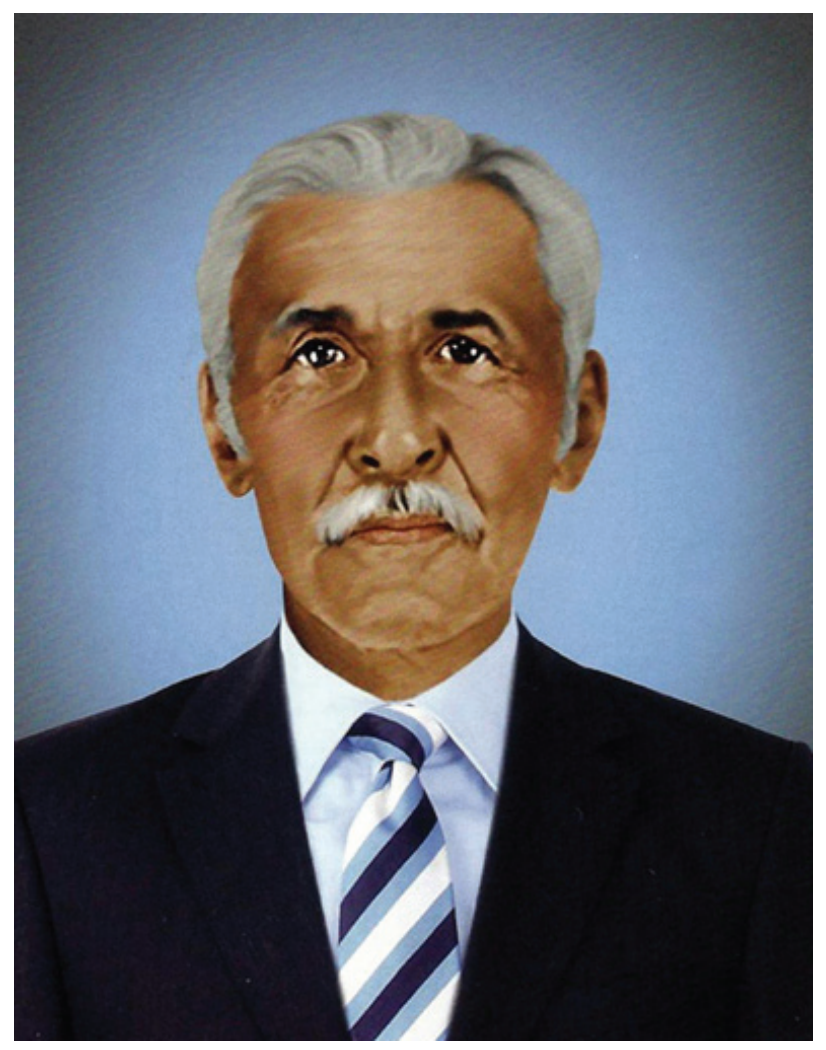




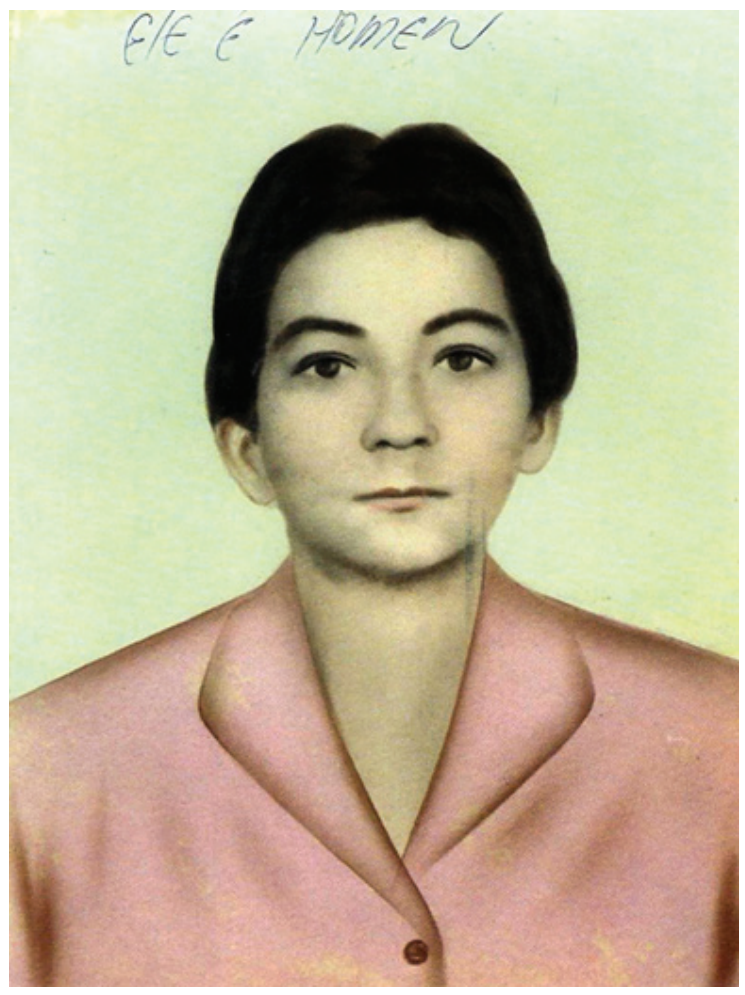

Fig. 2 - Fotopintura onde vemos a inscrição "ele é homem": alguns trabalhos perdiam a referência em relação aos retratados.

Fonte: coleção Titus Riedl, reproduzida do catálogo da Exposição "Fotopinturas" (CHIODETTO, 2011).

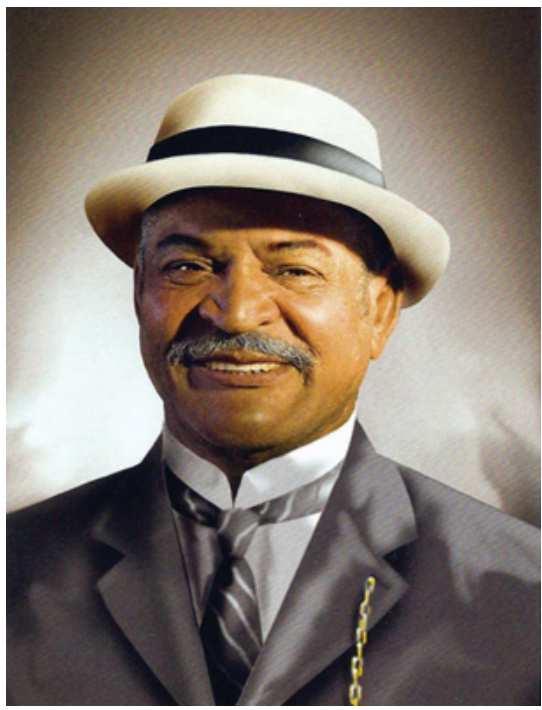

Fig. 3 - Fotos da série "Fotopintura Contemporânea", de Mestre Júlio Santos e Luiz Santos. Fonte: Mestre Júlio mestre da fotopintura (NAKAGAWA, 2010)

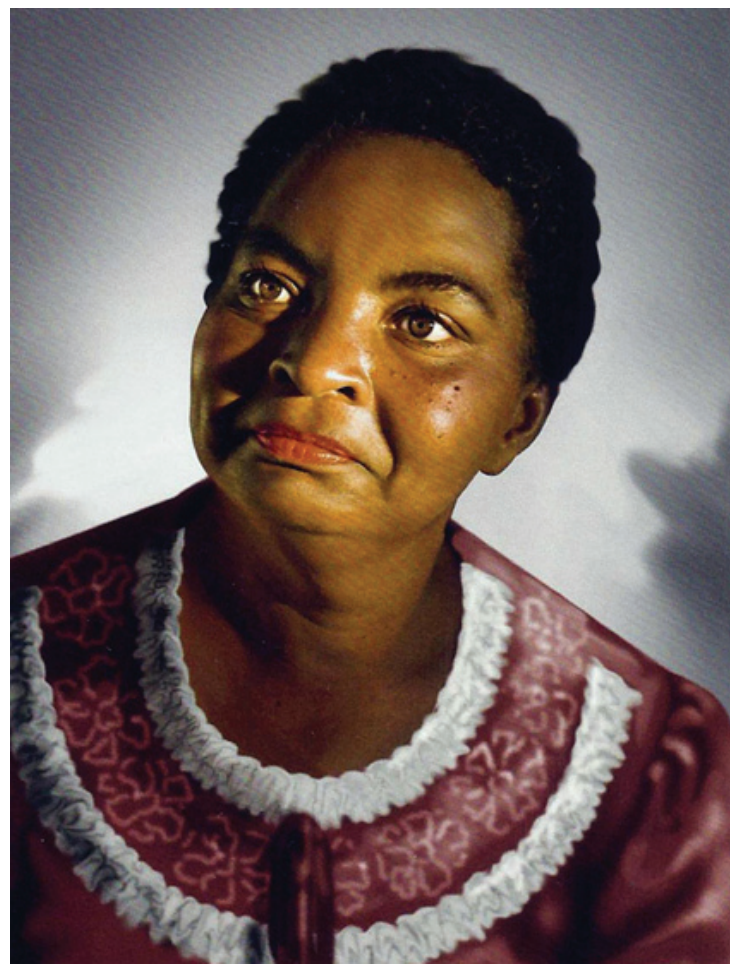




\section{RELEITURAS DE UMA OBSESSÃO HITCHCOCKIANA: origem, imagem, vertigem}

por Fernando de Mendonça

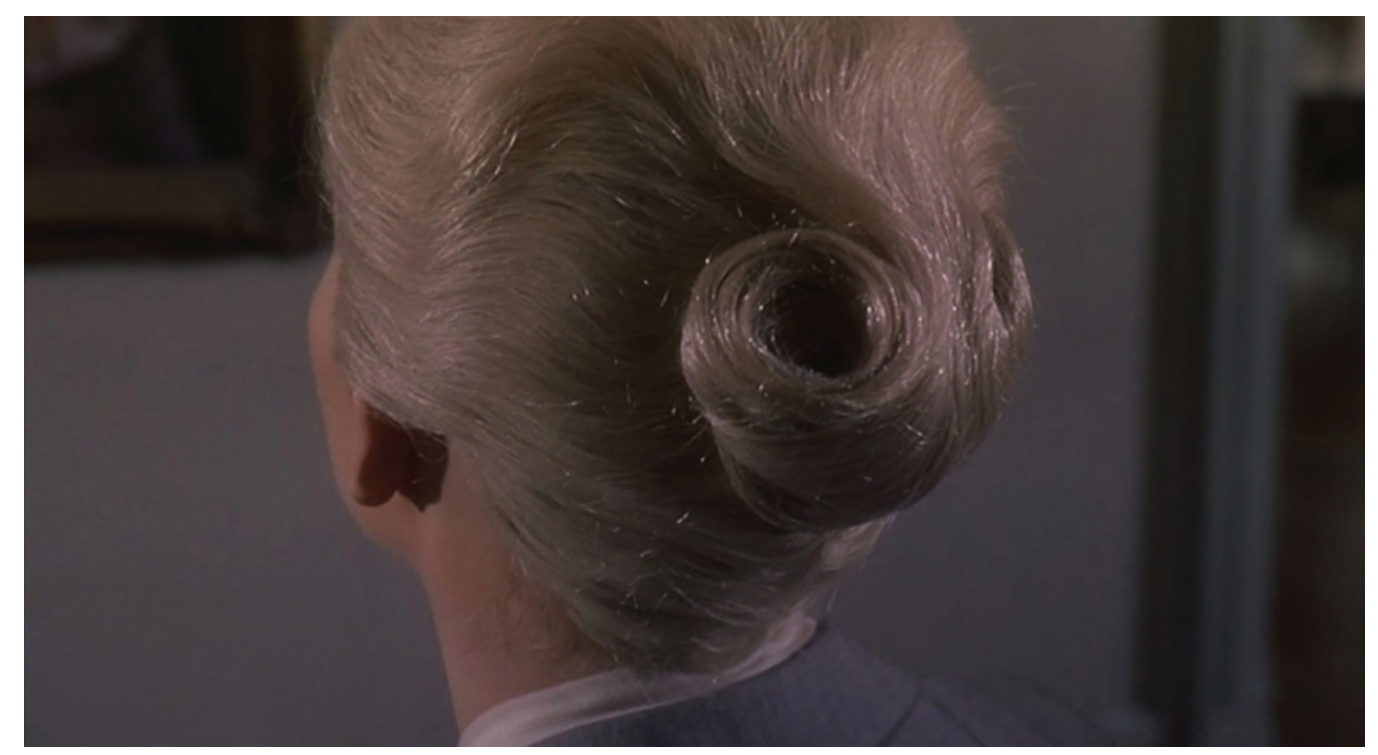

Fig. 1 - Vertigo (Alfred Hitchcock, 1958)

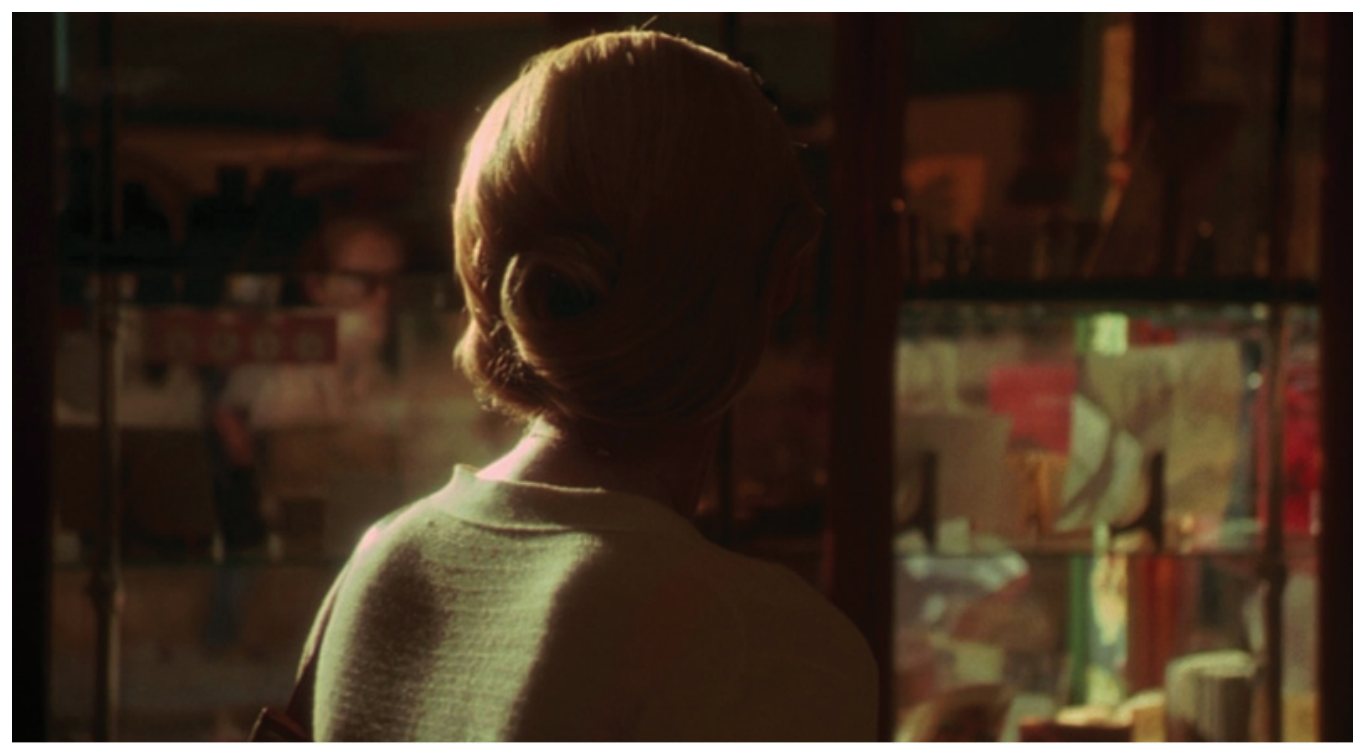

Fig. 2 - Io Sono L'Amore (Luca Guadagnino, 2009) 


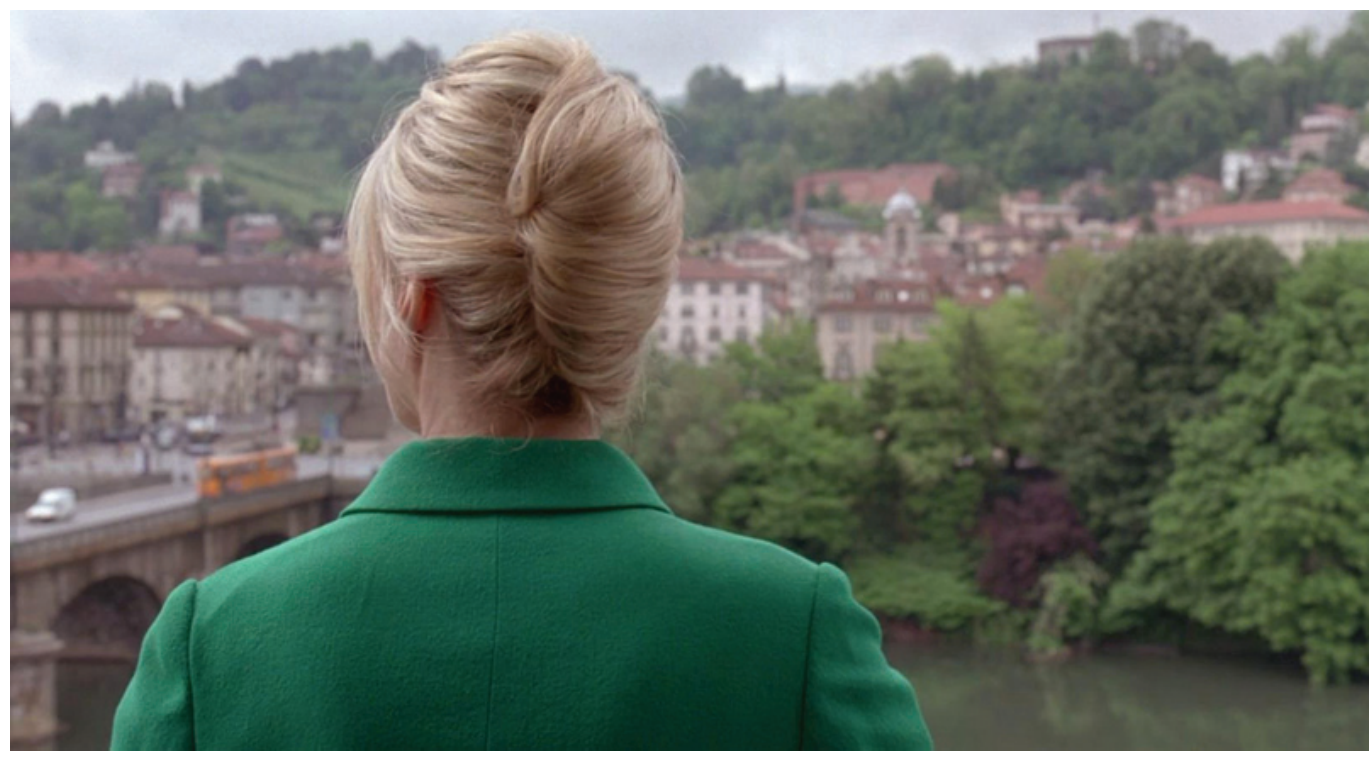

Fig. 3 - Giallo (Dario Argento, 2009)

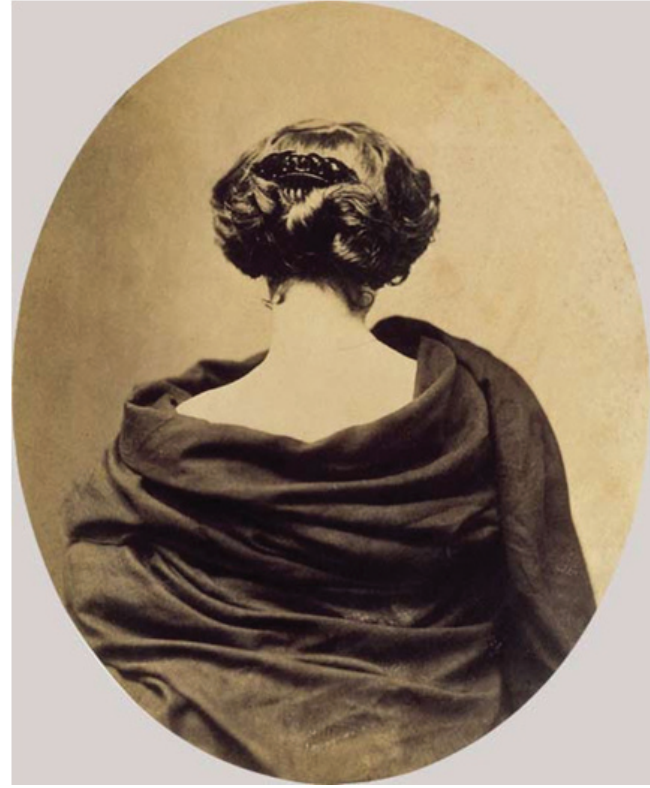

Fig. 4 - Fotografia de Félix Nadar (1820-1910)

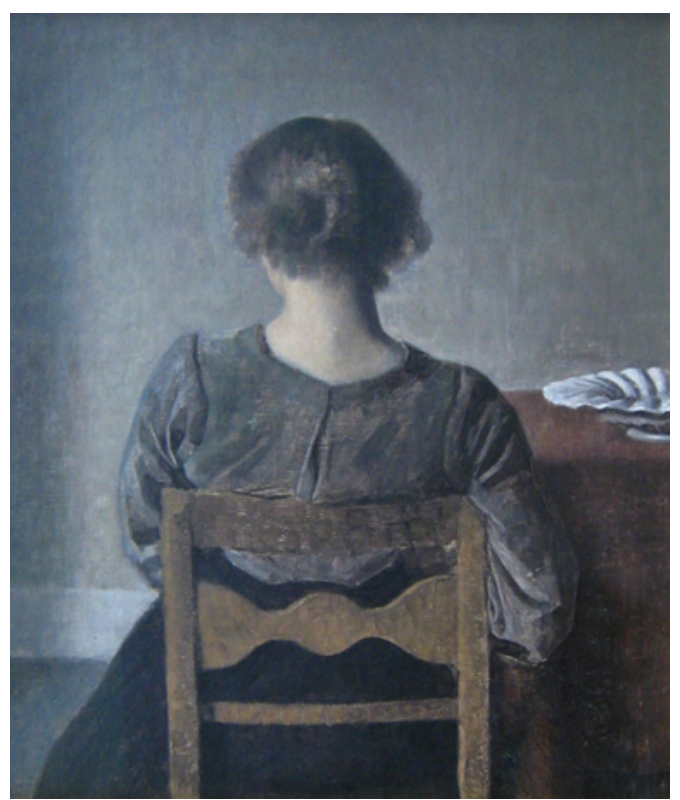

Fig. 5 - Hvile, Repos (Vilhelm Hammershoi, 1905) 
SOBRE UMA FOTOGRAFIA DE GUERRA: fronteiras do fotojornalismo contemporâneo

por Juliana Leitão

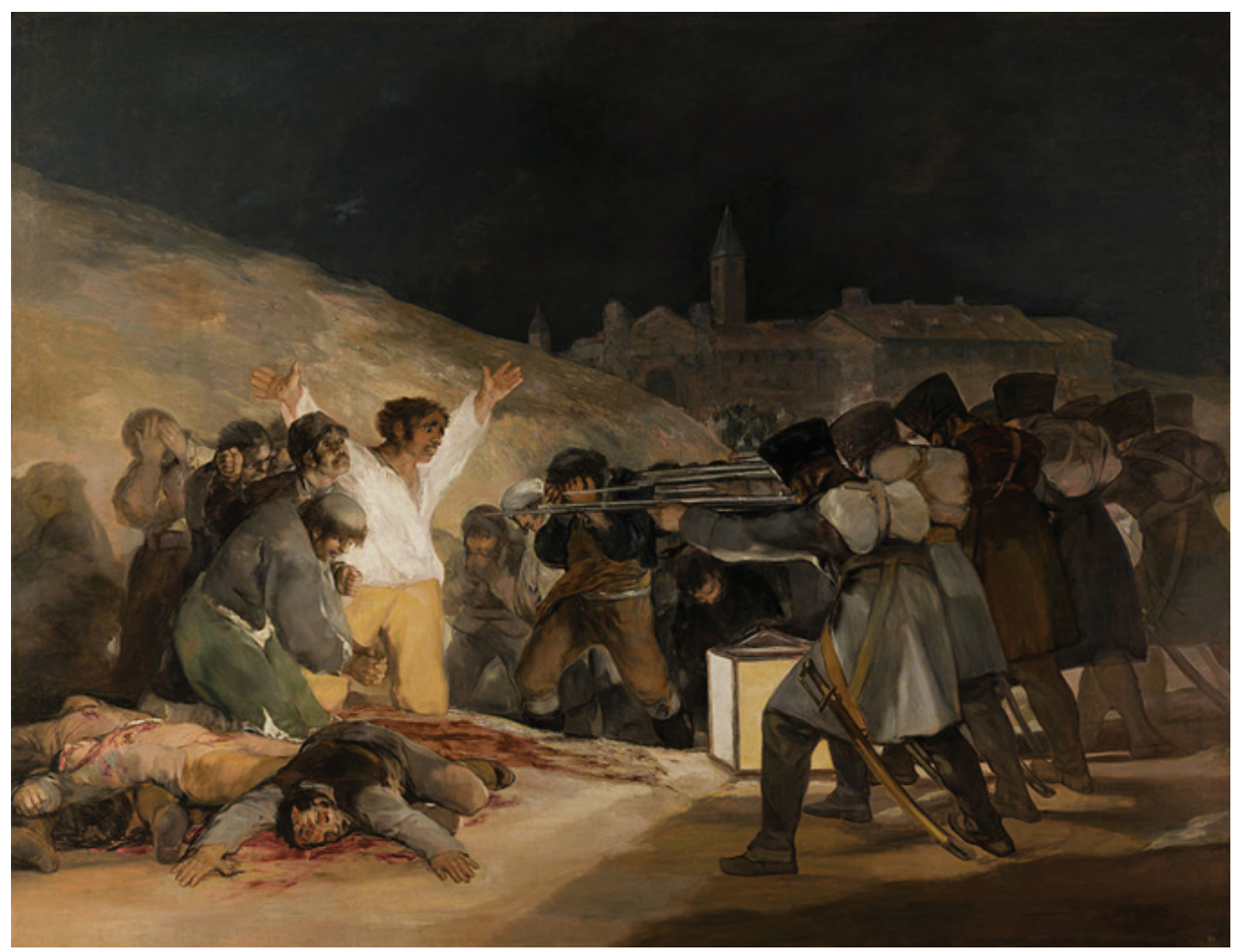

Fig 1 - Três de Maio de 1808, Francisco Goya 
O INSTANTE E O MOVIMENTO: a influência da fotografia de Muybridge e Marey

por Marcos Buccini

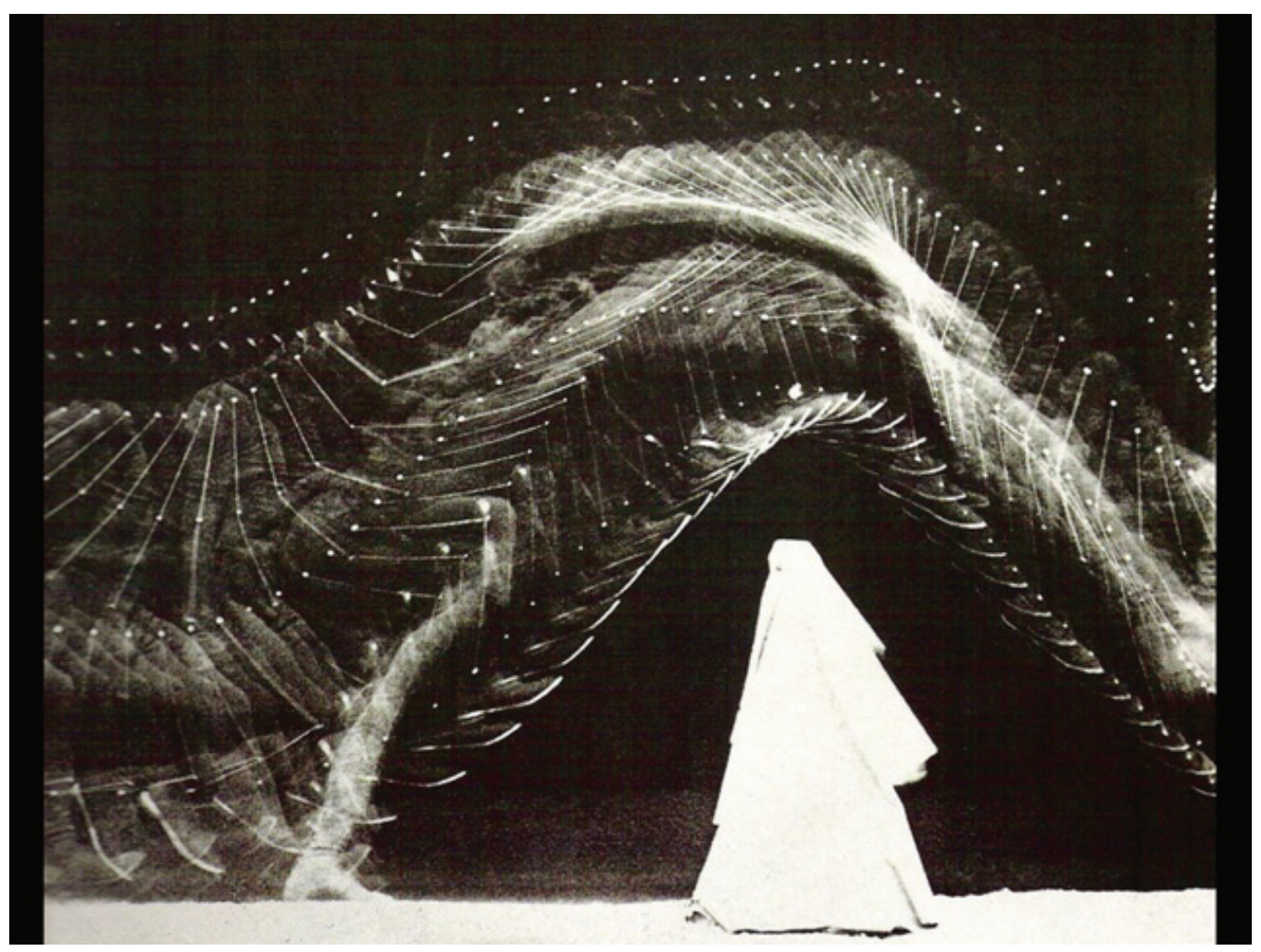

Fig. 1 - Primeiras cronofotografias de Étienne- Jules Marey.

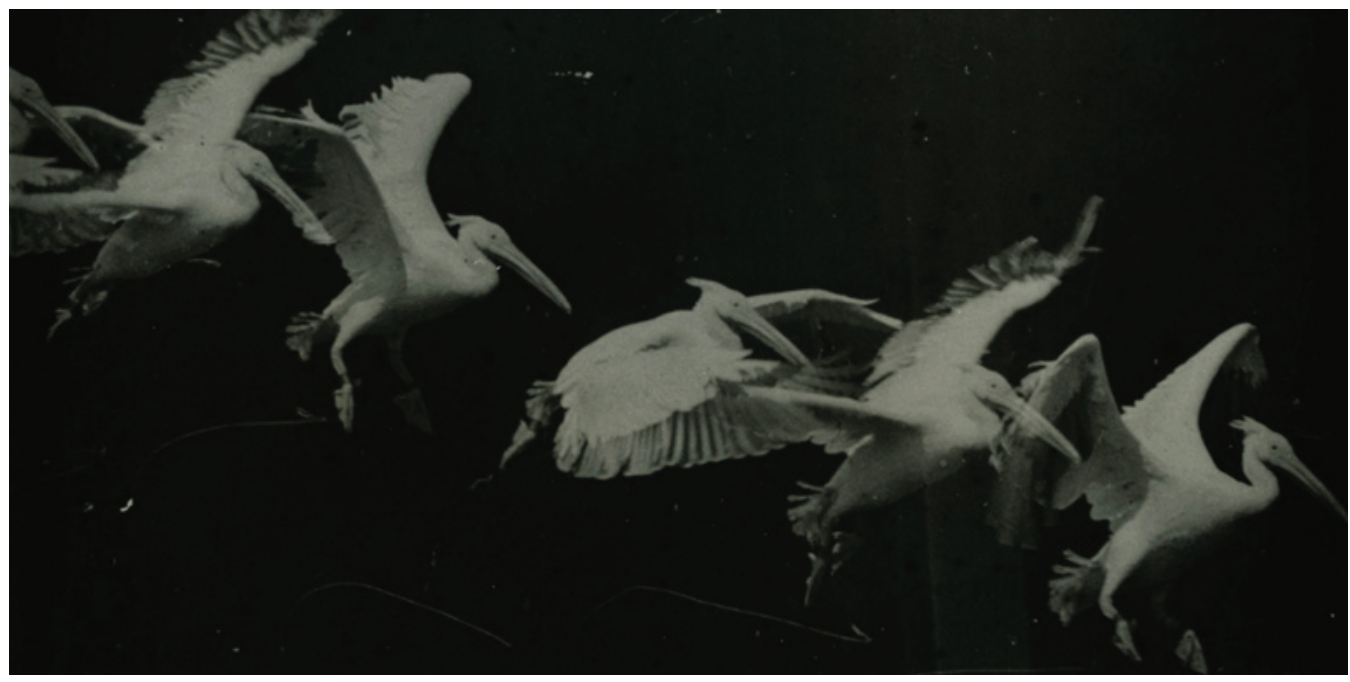

Fig. 2 - Cronofotografia que registra o vôo de um pelicano. 


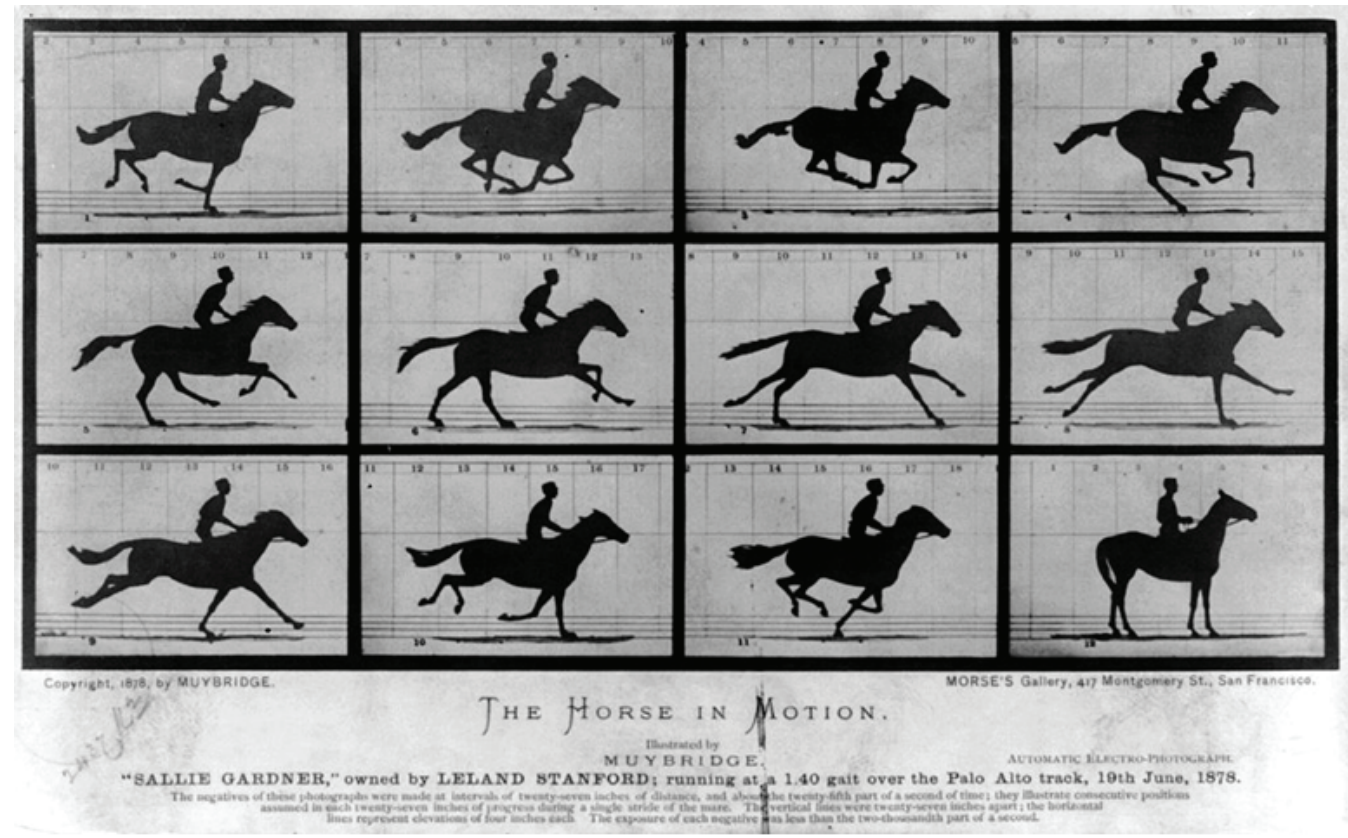

Fig. 3 - The Horse in motion, sequência de fotos de Muybridge.

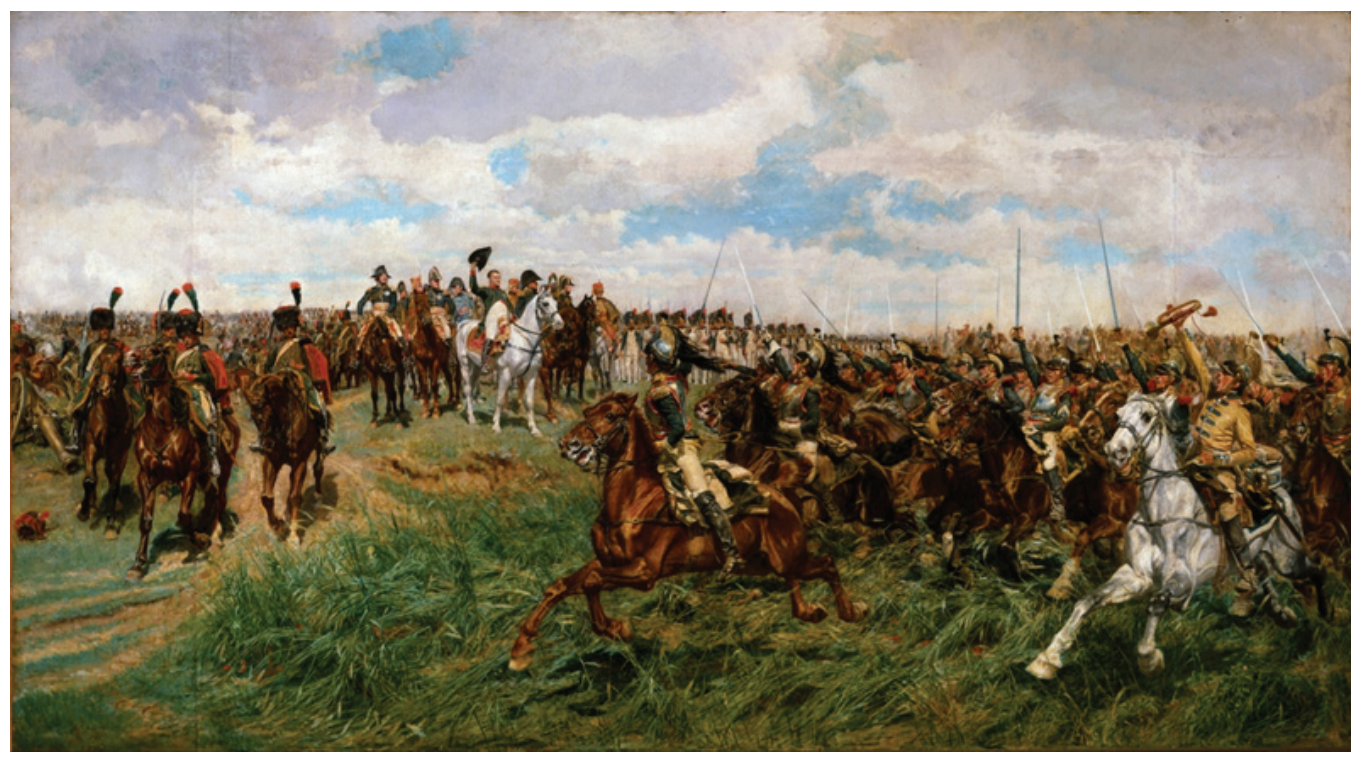

Fig. 4 - Quadro 1807 do pintor Jean-Louis-Ernest Meissonier. 


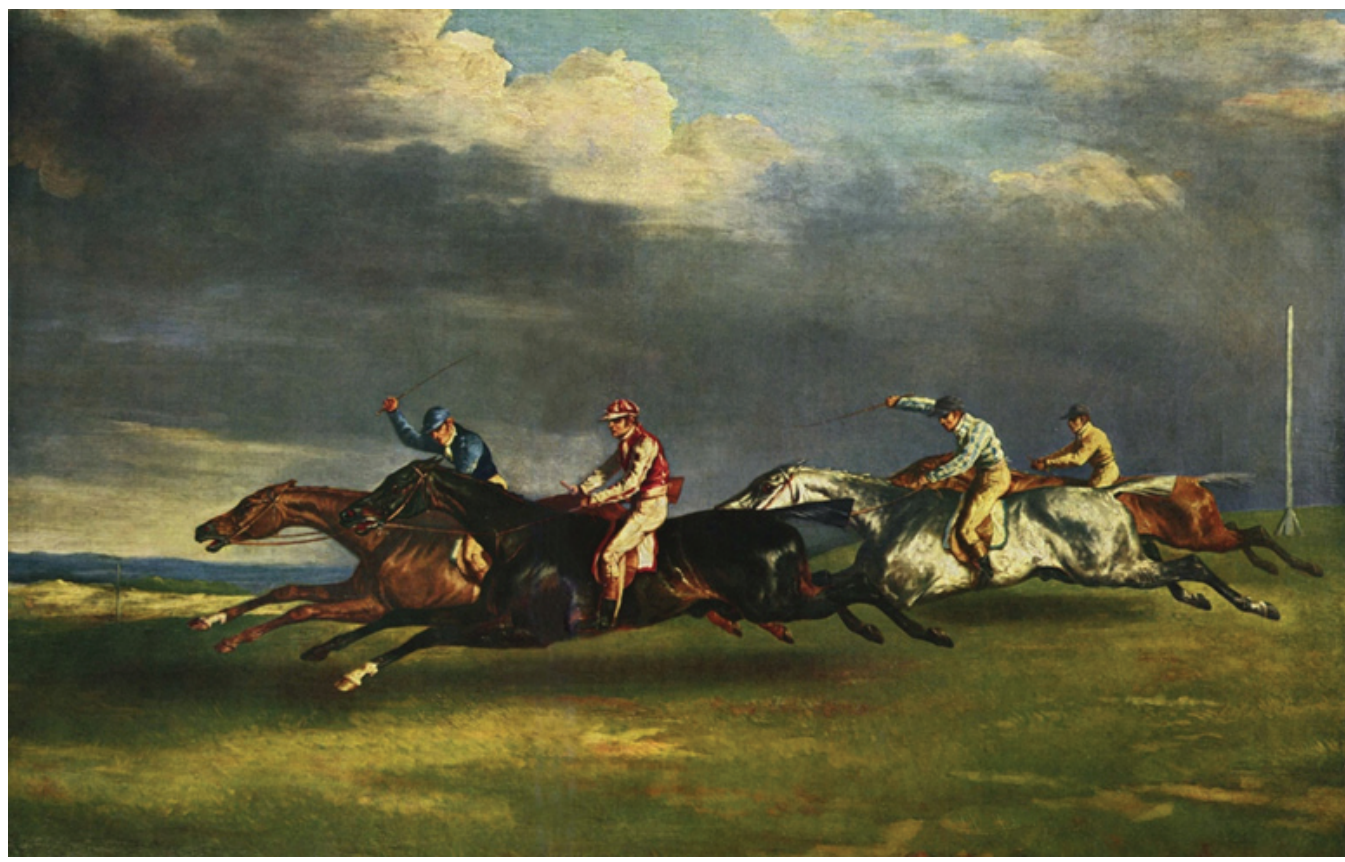

Fig. 5 - 'Corrida de Cavalos em Epson' de Théodore Géricault.

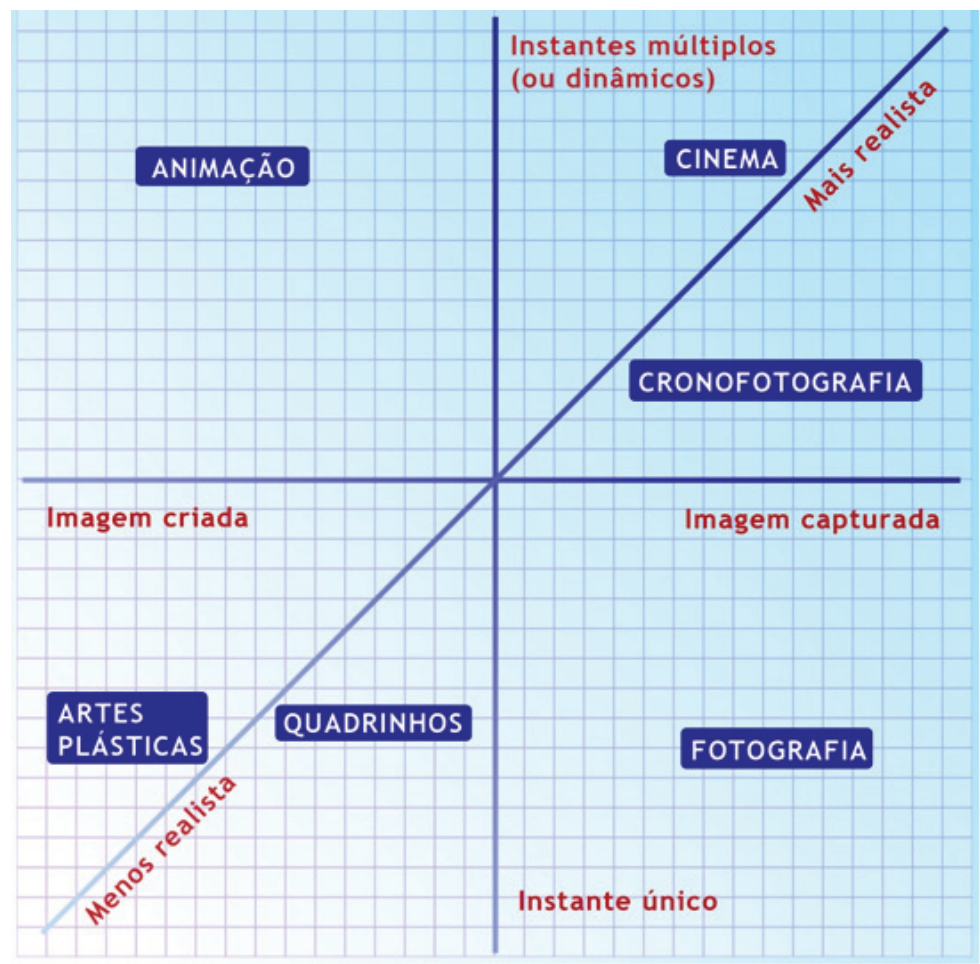

Fig. 6 


\section{O LITERÁRIO EM FOTOGRAFIAS DE STEVE MCCURRY OU A ELO- QUÊNCIA DO OLHAR EM PORTRAITS}

por Patricia Tenório

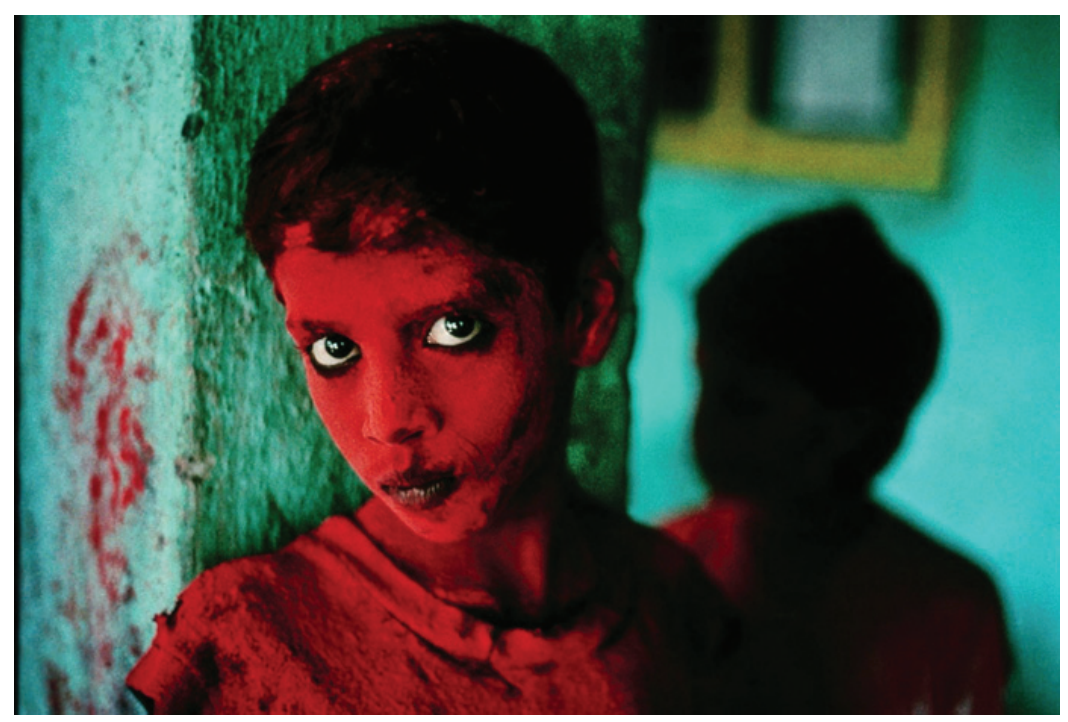

Fig. 1 - Bombay, India, 1997

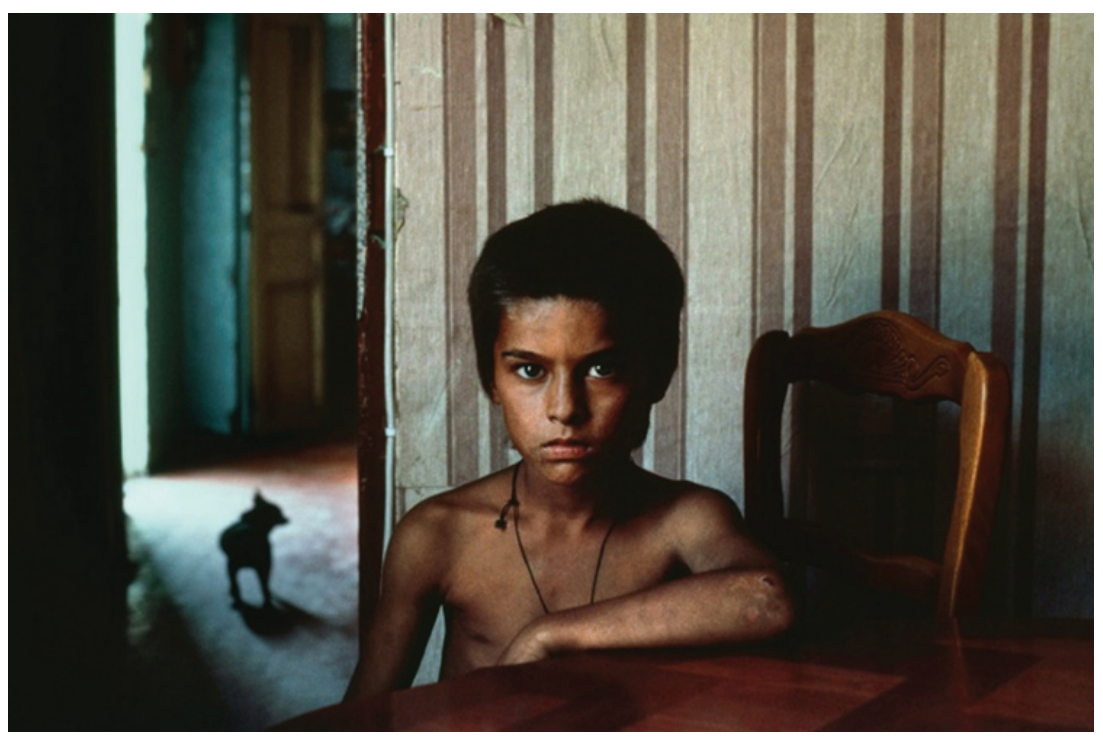

Fig. 2 - Marseille, France, 1989 


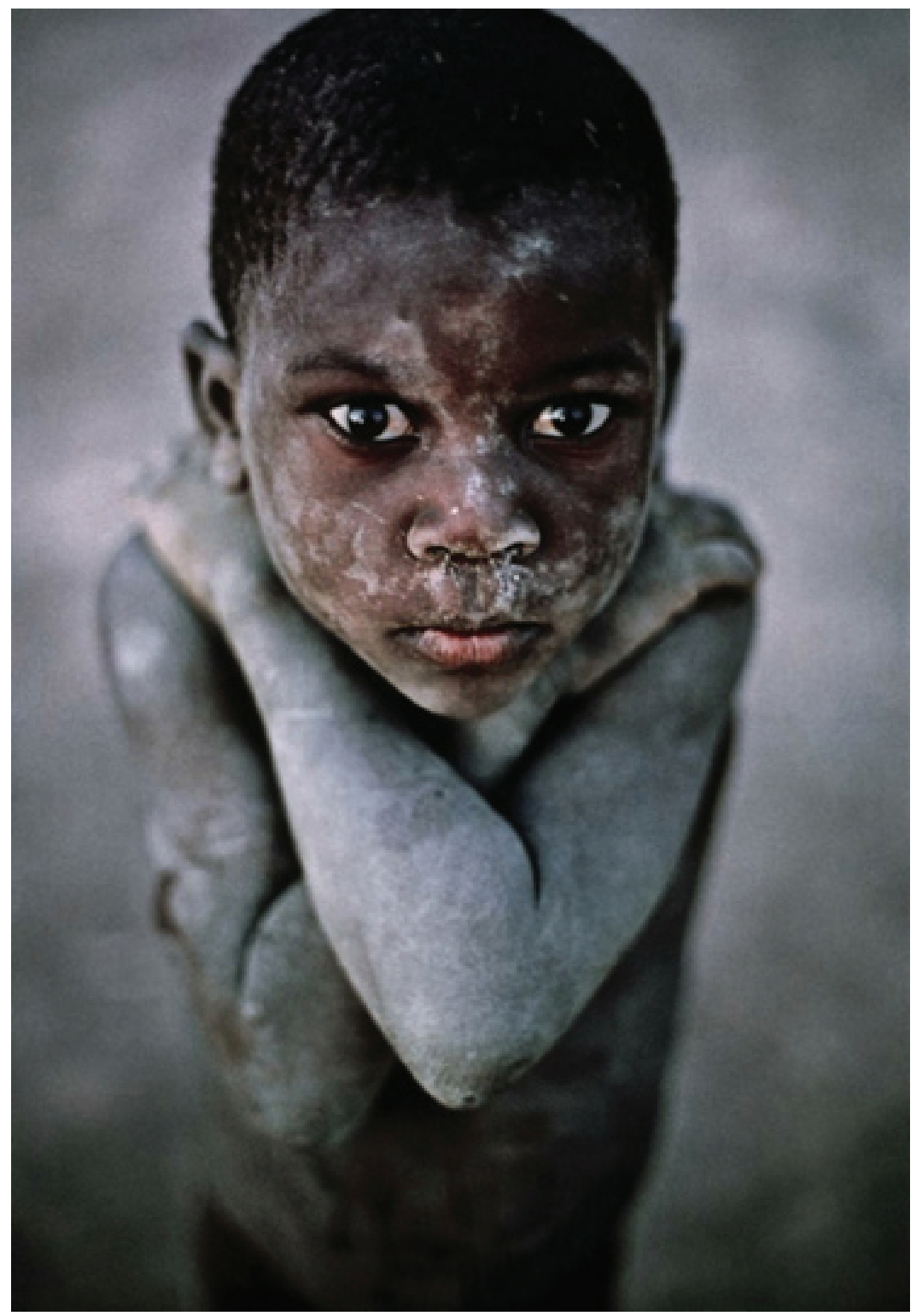

Fig. 3 - Timbuktu, Mali, 1987 


\title{
GUS VAN SANT E A IMAGEM-NÉVOA
}

\author{
por Rafael Dias
}

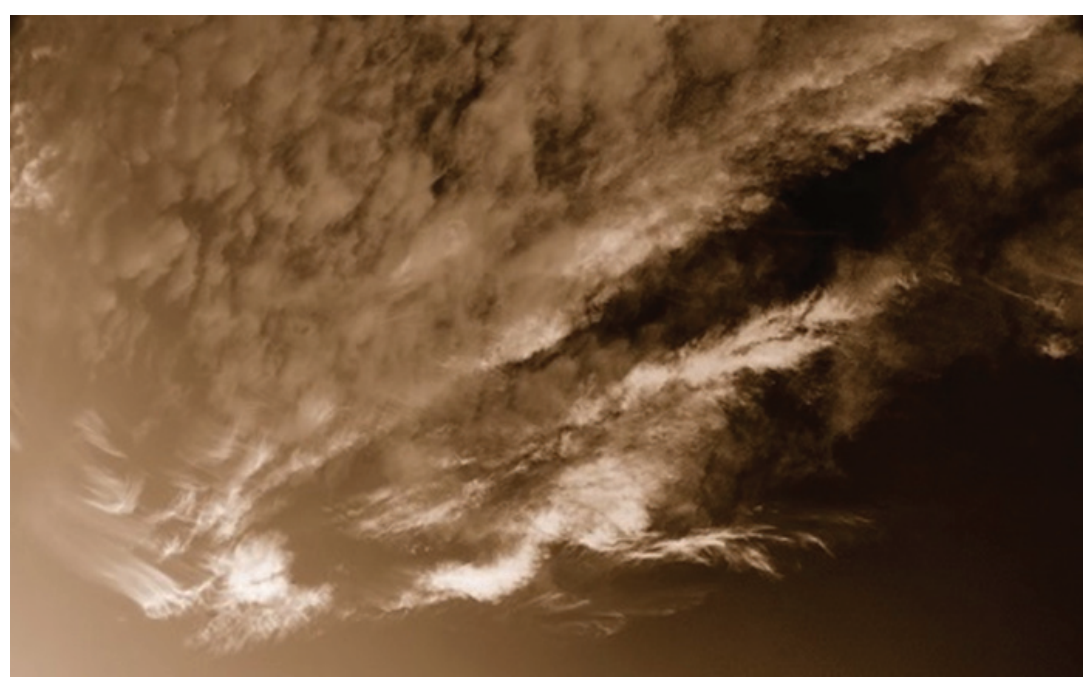

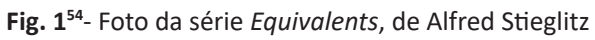

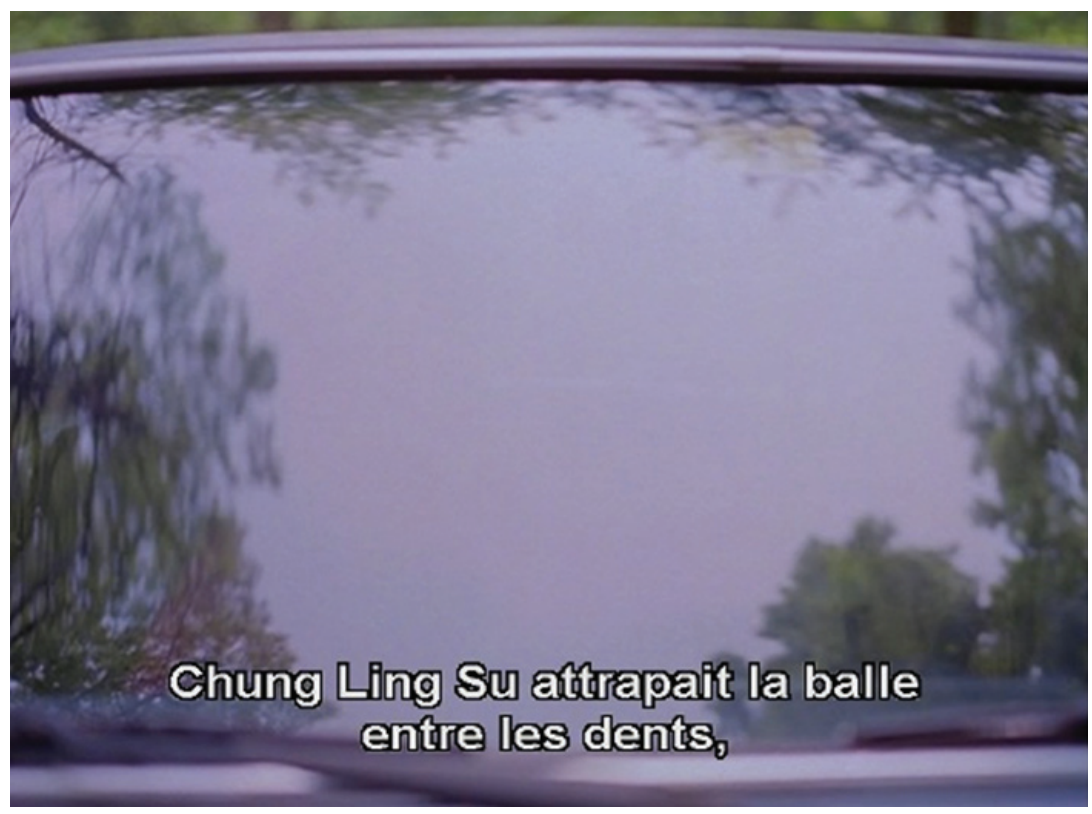

Fig. $2^{55}$ - Frame de Últimos Dias, de Gus Van Sant

54 http://www.paulmphotography.com/equivalents/1280/DSC_4967_800.jpg.

55 Este frame do filme, assim como os próximos deste artigo, foi extraído do DVD da distribuidora MK2 Éditions, lançado em box office no mesmo ano em que foi divulgado, em 2005. 


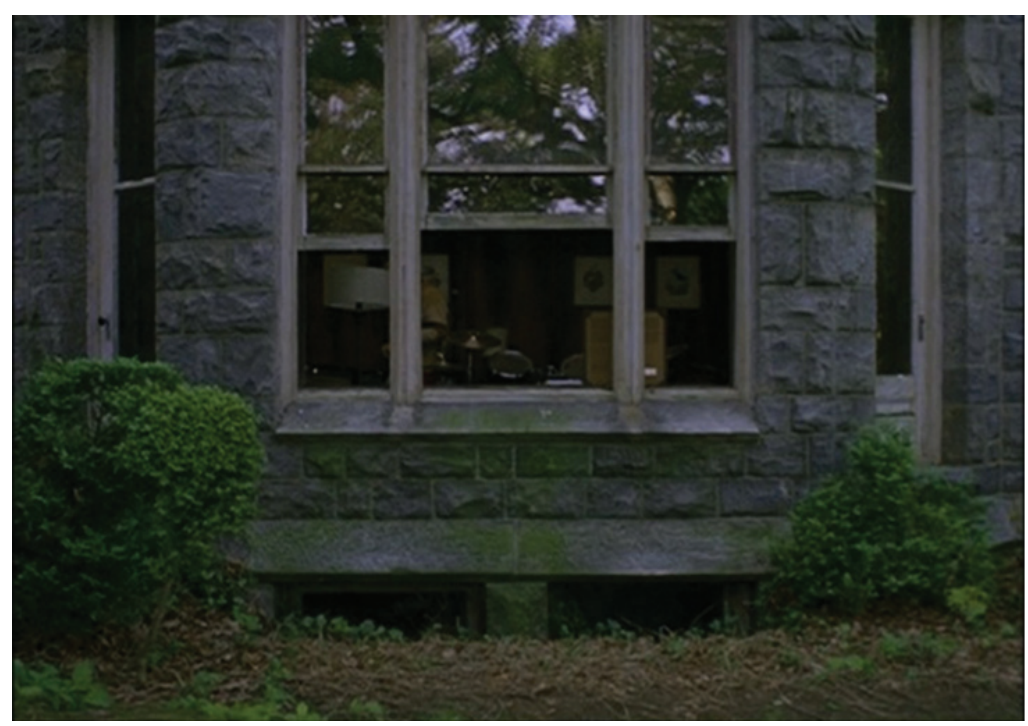

Fig. 3

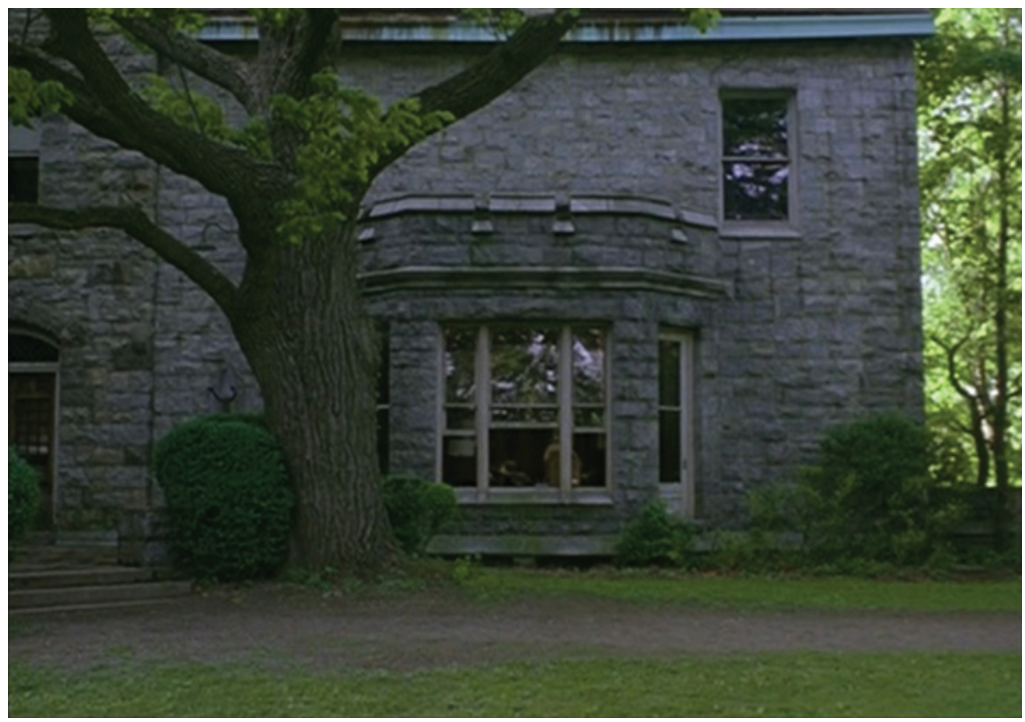

Fig. 4 


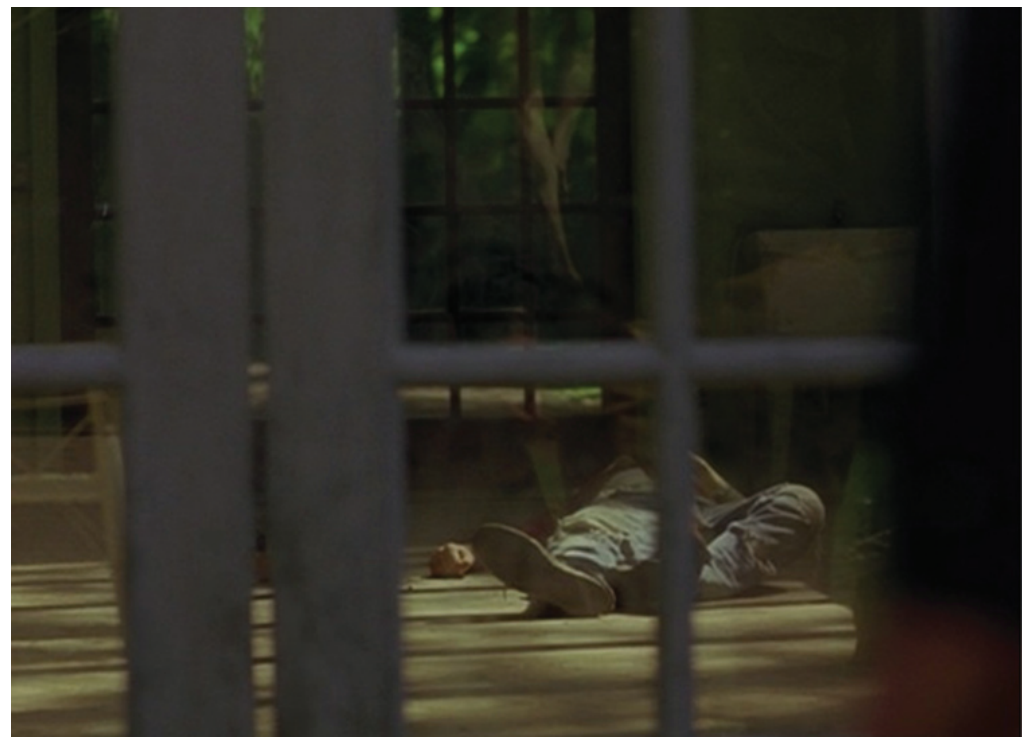

Fig. 5 


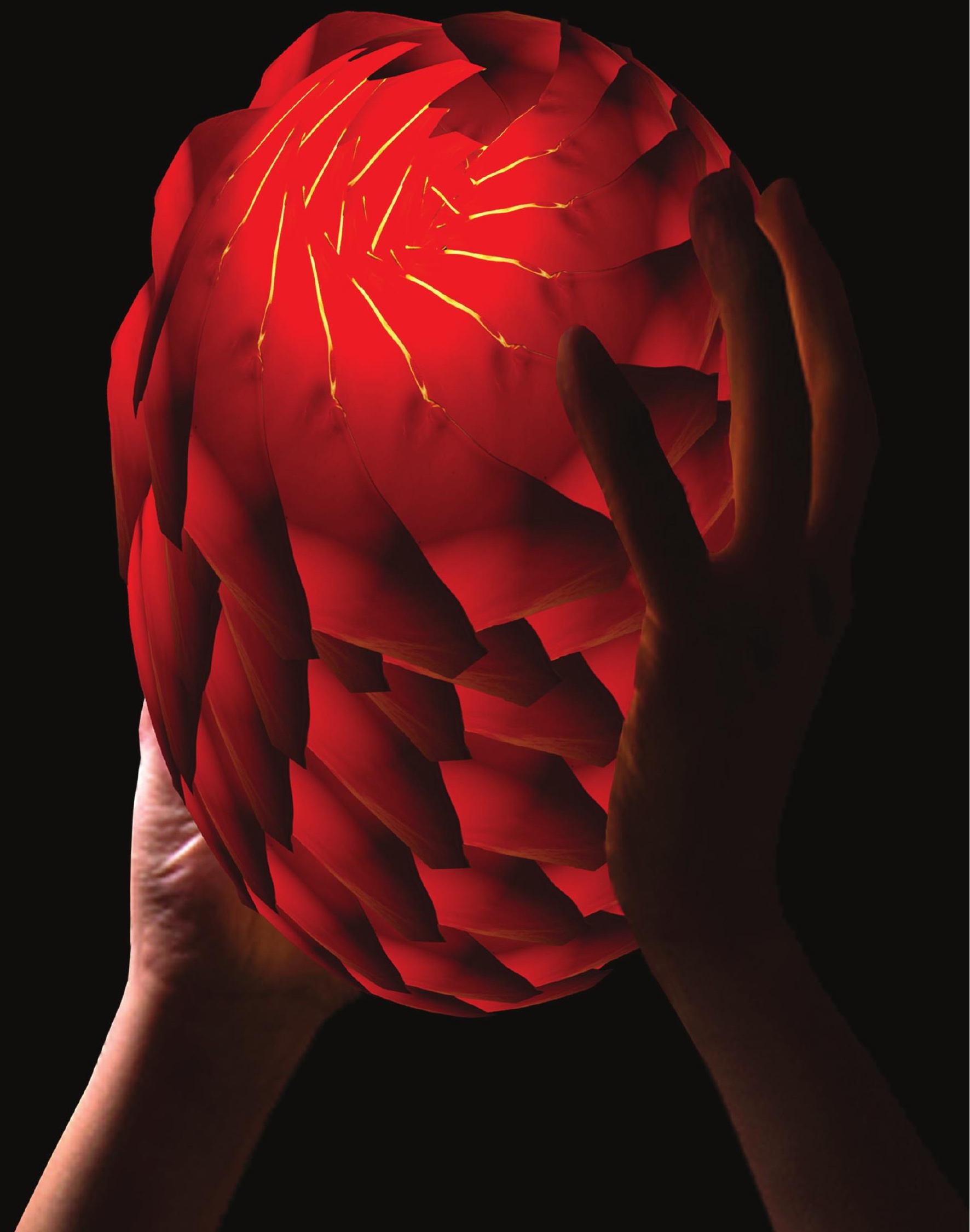

